Rev. Bras. Saúde Prod. Anim., Salvador, v.16, n.3, p.523-534 jul./set.., $2015 \quad \underline{\text { http://www.rbspa.ufba.br }}$

\title{
Caracterização da diversidade genética de ovinos Santa Inês em fazendas do Estado do Piauí
}

\author{
Genetic diversity characterization of Santa Inês sheep Piaui State farms
}

\author{
MARQUES, Iolly Tábata Oliveira ${ }^{1 *}$; SARMENTO, José Lindenberg Rocha ${ }^{2}$; \\ BIAGIOTTI, Daniel ${ }^{3}$; VALE, Kaline Aguiar Gonzalez ${ }^{1}$; CARVALHO, Kátia Silene \\ Sousa ${ }^{1}$; BRITTO, Fábio Barros ${ }^{4}$
}

\footnotetext{
${ }^{1}$ Universidade Federal do Piauí, Departamento de Agronomia, Centro de Ciências Agrárias, Campus Socopo, Teresina, Piauí, Brasil.

${ }^{2}$ Universidade Federal do Piauí, Departamento de Zootecnia, Centro de Ciências Agrárias, Campus Socopo, Teresina, Piauí, Brasil.

${ }^{3}$ Universidade Federal do Piauí, Colégio Técnico de Bom Jesus, Bom Jesus, Piauí, Brasil.

${ }^{4}$ Universidade Federal do Piauí, Departamento de Biologia, Centro de Ciências da Natureza, Campus Ministro Petrônio Portela, Teresina, Piauí, Brasil.

*Endereço para correspondência: tabata_iolly@hotmail.com
}

\section{RESUMO}

Objetivou-se avaliar a diversidade genética de ovinos Santa Inês em fazendas no Estado do Piauí, utilizando marcadores RAPD. Foram analisados 164 espécimes pertencentes a seis municípios das mesorregiões Centro-Norte e Sudoeste. Após a obtenção do DNA, avaliou-se o potencial de 34 iniciadores, dos quais apenas cinco mostraram bandas passíveis de análise. Foram amplificados 37 locos distintos, sendo 36 polimórficos. Apesar do alto polimorfismo geral $(97,2 \%)$ a taxa de polimorfismo intrapopulacional foi reduzida (média = $69,82 \%$ /população), mostrando que o conjunto dos rebanhos apresenta alta diversidade, mas que cada população isolada pode estar sofrendo efeitos da endogamia. Os índices de diversidade genética (Hs) e de endogamia ( $f$ ) apresentaram, respectivamente, valores de 0,289 e 0,172. Ambos indicaram excesso de homozigotos e consanguinidade positiva dentro das fazendas. A composição dos rebanhos amostrados quase exclusivamente por fêmeas pode ser a justificativa para esses resultados, onde as proles são compostas principalmente por meioirmãos. Os resultados acima citados foram confirmados pelos testes de AMOVA $\left(\Phi_{\mathrm{ST}}=\right.$ $0,199)$, que mostrou diferenças genéticas significativas entre fazendas, e pelas análises do programa STRUCTURE, que indicaram a presença de três grupos genéticos distintos, podendo esta ser uma evidência da presença de animais pertencentes ao "Novo Santa Inês", entre os ovinos amostrados.

Palavras-chaves: caracterização molecular, estrutura populacional, marcadores moleculares, Ovis aries, RAPD

\section{SUMMARY}

This study aimed to evaluate the genetic diversity of Santa Inês sheep in Piauí state farms using RAPD markers. A total of 164 specimens belonging to six cities of Central-Northern and Southwestern regions were analyzed. After isolating the DNA, we assessed the potential of 34 primers, of which only five showed bands with sufficient resolution. Thirty-seven distinct loci were amplified, of which 36 were polymorphic. Despite the overall high polymorphism $(97.2 \%)$ the rate of polymorphism within each population was reduced (mean $=69.82 \% /$ population), showing that all the herds have a high diversity but that each isolated population may be suffering the effects of inbreeding. The indices of genetic diversity (Hs) and inbreeding ( $f$ ) showed, respectively, values of 0.289 and 0.172 . Both showed homozygote excess and positive consanguinity within the farms. The composition of the sampled herds almost 
exclusively by females may be the explanation for these results, where half-brothers compose most of the offspring. The above results were confirmed by AMOVA tests $\left(\Phi_{\mathrm{ST}}=0.199\right)$, which showed significant genetic differences between farms. Also, the analysis of STRUCTURE software indicated the presence of three distinct genetic groups, which may characterize the occurrence of animals belonging to the "New Santa Inês" among the sampled sheep.

Keywords: molecular characterization, molecular markers, Ovis aries, population structure, RAPD

\section{INTRODUÇÃO}

As raças de ovinos trazidas para América do Sul tiveram procedência europeia e africana. Com o passar dos anos esses animais foram se adaptando às condições locais e adquirindo grande rusticidade (PAIVA et al., 2005a). No Brasil, a ovinocultura destacou-se inicialmente na produção de lã, na região Sul do país. Porém, após uma crise no mercado da lã, a região Nordeste ganhou evidência com a pecuária de corte de subsistência (VIEIRA et al., 2000; VIANA, 2008).

Neste cenário, o Estado do Piauí apresenta um efetivo de cerca de 1,4 milhão de ovinos, onde a raça Santa Inês é uma das que mais se destaca pelo potencial genético, porte, adaptabilidade e boa aceitação a diferentes sistemas de criação (BIAGIOTTI et al., 2013). No entanto, a busca do aumento da produtividade tem incentivado os cruzamentos com outras raças comerciais (ARANDAS et al., 2012; GUIMARÃES et al., 2012), podendo ocasionar a perda de variabilidade do germoplasma nativo. Nota-se que o abandono dos rebanhos nordestinos tem se tornado significativo, levando à diminuição do potencial genético local e aumentando o risco de extinção (RODRIGUES et al, 2009).
Diante deste fato, a caracterização de rebanhos Santa Inês, por meio de marcadores moleculares, torna-se importante para direcionar estratégias de conservação (FARID et al., 2000; MENEZES et al., 2006). Além de atuarem como ferramentas de identificação, os marcadores moleculares fornecem estimativas de distâncias genéticas para a determinação de índices de coancestria e endogamia (TENEVA, 2009; SILVA et al., 2011). Dentre eles, um dos mais utilizados são os RAPD (Random Amplified Polymorphic DNA), apresentando alto potencial na discriminação de distintos estoques genéticos, sendo aplicados em trabalhos de diversidade de ruminantes e outras espécies (ALBUQUERQUE et al., 2006). Embora outros tipos de marcadores venham sendo mais amplamente aplicados para estudos do tipo, uma avaliação prévia da variabilidade da raça Santa Inês pode ser obtida de forma rápida com os RAPD. No Piauí, foram encontrados apenas avaliações baseadas em dados fenotípicos (COSTA JÚNIOR et al, 2006; BIAGIOTTI et al., 2013) e informações de pedigree (REGO NETO et al, 2014), sendo que todos os estudos apontaram para $\mathrm{o}$ aumento da endogamia.

Assim, devido à escassez de dados genotípicos, o presente trabalho trás uma avaliação preliminar da diversidade genética de ovinos puros da raça Santa Inês, em seis fazendas do Estado do Piauí utilizando marcadores RAPD.

\section{MATERIAL E MÉTODOS}

Foram coletadas amostras de pelos de 164 ovinos da raça Santa Inês oriundos de seis fazendas no estado do Piauí, localizadas em seis municípios: Cristino Castro (33 animais), Bom Jesus (36 
animais), Redenção do Gurguéia (13 animais), São Raimundo Nonato (22 animais), Teresina (30 animais) e Campo Maior (30 animais) (Figura 1). Todas as fazendas apresentam animais registrados como Puros de Origem na APICOVI (Associação Piauiense de Criadores de Ovinos). Os pelos foram coletados próximo à região caudal do animal, colocados em envelopes identificados, individualmente, por fazenda/localidade e transportados em caixa térmica até o Laboratório de Genética e Conservação de Germoplasma da Universidade Federal do Piauí, Campus Prof ${ }^{a}$. Cinobelina Elvas, onde foram processados, posteriormente. $\mathrm{O}$ material coletado foi acondicionado à aproximadamente $4^{\circ} \mathrm{C}$ até o momento da extração de DNA. As coletas foram realizadas entre os anos de 2010 e 2013.

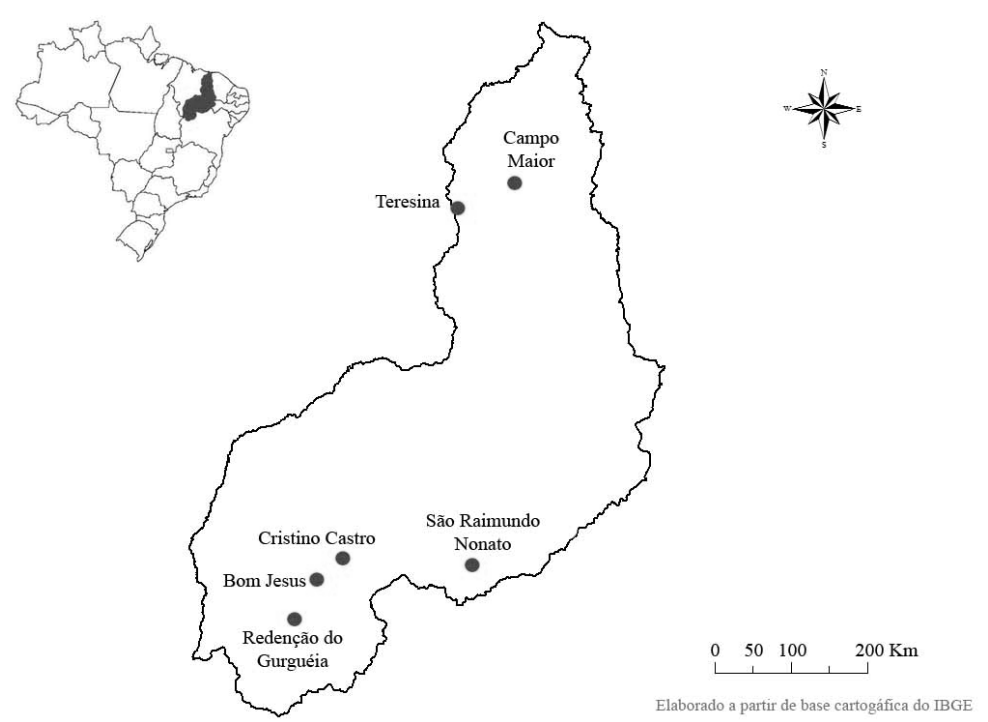

Figura 1. Mapa do Estado do Piauí destacando municípios onde foram realizadas as coletas de pelos em ovinos Santa Inês

O DNA dos bulbos pilosos foi extraído por meio do kit de extração Qiagen QIAamp® DNA Tissue Kit seguindo as especificações do fabricante.

Os resultados das extrações foram verificados através de eletroforese em gel de agarose a $0,8 \%$ e a concentração das amostras foi ajustada para aproximadamente $10 \mathrm{ng} / \mu \mathrm{L}$ utilizando marcador $\lambda \mathrm{DNA}$ nas concentrações de 10 e $25 \mathrm{ng} / \mu \mathrm{L}$. Em seguida as amostras foram estocadas em freezer a $-20^{\circ} \mathrm{C}$ para procedimentos posteriores.
Foram avaliados 34 primers RAPD, desenhados pela University of Britsh Columbia os quais foram testados em amostras de DNA de ovinos Santa Inês escolhidas aleatoriamente. Para cada um dos primers foi realizada Reação em Cadeia da Polimerase (PCR) preliminar, em volume de $10 \mu \mathrm{L}$, onde foram testados os seguintes componentes: tampão de PCR a $1 \times ; \mathrm{MgCl}_{2}$ variando de a 2,0 a 3,4 mM; dNTP a $0,8 \mathrm{mM}$; primer variando de 0,5 a $0,8 \mu \mathrm{M}, 1 \mathrm{U}$ de Taq DNA polimerase; $0,5 \mu \mathrm{L}$ de 
Rev. Bras. Saúde Prod. Anim., Salvador, v.16, n.3, p.523-534 jul./set.., $2015 \quad \underline{\text { http://www.rbspa.ufba.br }}$

DNA genômico ( $~ 5$ ng $)$ e água ultrapura q.s.p. $10 \mu \mathrm{L}$.

A amplificação do DNA foi realizada com desnaturação inicial de 5 minutos a $94^{\circ} \mathrm{C}$, seguida de 36 ciclos com desnaturação de 40 segundos a $94^{\circ} \mathrm{C}, 1$ minuto para anelamento com temperaturas variando de 34 a $40^{\circ} \mathrm{C}$ e 2 minutos a $72^{\circ} \mathrm{C}$ para extensão. Foi realizada uma etapa de extensão final de 10 minutos a $72^{\circ} \mathrm{C}$.

$\mathrm{O}$ resultado das amplificações foi avaliado com eletroforese em gel de agarose a $1,5 \%$, sendo o material corado com banho em brometo de etídio e visualizado em Transluminador L.PIX (Loccus Biotecnologia). Após os testes, apenas cinco dos marcadores forneceram resultados satisfatórios, onde foi possível verificar a presença de bandas nítidas no gel e a presença de polimorfismos (Tabela 1). Para estes marcadores estabeleceu-se a concentração de $\mathrm{MgCl}_{2}$ a $3,4 \mathrm{mM}$ e de primer a $8,0 \mu \mathrm{M}$. A temperatura de anelamento fixada para os cinco marcadores utilizados foi de $36^{\circ} \mathrm{C}$.

A genotipagem das amostras foi realizada por meio de eletroforese em gel de agarose a 1,5\%, seguindo os mesmos procedimentos descritos no item anterior.

As informações moleculares obtidas nos géis foram convertidas em dados binários com a presença ou ausência de bandas sendo codificadas, respectivamente, com valores 1 e 0 .

Com os dados gerados, verificou-se a taxa de polimorfismo, onde foi realizada a contagem de locos polimórficos entre o número total de locos amplificados. Além disso, a taxa de polimorfismo foi avaliada para cada população isoladamente.

O programa HICKORY 1.1, que implementa o método Bayesiano descrito por Holsinger et al. (2002), foi usado para estimar o índice de diversidade genética (Hs). Também foram estimados os índices $\theta_{\text {II }}$ (análogo do $\mathrm{F}_{\mathrm{ST}}$ de Wright) e $f$ (análogo do $\mathrm{F}_{\mathrm{IS}}$ ) para a avaliação das diferenças genéticas interpopulacionais e níveis de endogamia, respectivamente. Foram utilizadas 25.000 simulações de Cadeias de Markov Monte Carlo com burn in de 5.000. A confiabilidade dos dados foi estimada a partir do intervalo de confiança entre $2,5 \%$ a $97,5 \%$ (IC95\%).

A análise de variância molecular (AMOVA) foi realizada para as seis populações para determinar $\Phi_{\mathrm{ST}}$ (outro análogo $\mathrm{F}_{\mathrm{ST}}$ ) utilizando o programa ARLEQUIN 3.0 (EXCOFFIER et al., 2005). A AMOVA foi configurada agrupando-se as populações em duas regiões, de acordo com sua proximidade geográfica, como segue: Grupo 1 (Mesorregião Sudoeste): Cristino Castro, Bom Jesus, Redenção do Gurguéia e São Raimundo Nonato; Grupo 2 (Mesorregião Centro-Norte): Teresina e Campo Maior. Também foram calculados os valores de $\Phi_{\mathrm{ST}-p a r-a-p a r}$ entre cada localidade para a realização do teste de Mantel, que mostra a proporção da variação genética explicada pela variação geográfica. $\mathrm{O}$ nível de significância do teste foi calculado após 1.000 permutações dos dados. A distância geográfica entre cada localidade foi calculada com o auxílio do programa GOOGLE EARTH (https://www.google.com/earth/). Estes dados também foram utilizados para a construção de um dendrograma utilizando o método Ligação Média entre Grupos (UPGMA) realizado no programa MEGA 5.02 (KUMAR et al., 2008).

O programa STRUCTURE versão 2.2 (PRITCHARD et al., 2000) foi utilizado para definir o número de grupos $(\mathrm{K})$ mais provável nas amostras coletadas, por meio de métodos Bayesianos sem informações a priori sobre a origem das amostras. Foram utilizadas 100.000 simulações de Cadeias de Markov 
Rev. Bras. Saúde Prod. Anim., Salvador, v.16, n.3, p.523-534 jul./set.., $2015 \quad \underline{\text { http://www.rbspa.ufba.br }}$ ISSN 15199940

Monte Carlo com burn in de 50.000 e modelo de ancestralidade admixture. Foram testados valores de $\mathrm{K}$ variando de 1 a 8. A determinação do $\mathrm{K}$ mais provável em relação aos propostos foi realizada utilizando valores de $\Delta \mathrm{K}$ segundo Evanno et al. (2005).

\section{RESULTADOS E DISCUSSÃO}

Os marcadores selecionados amplificaram um total de 37 locos (bandas), sendo 36 polimórficos (Tabela 1). Foi observada variação de 6 a 9 locos amplificados entre os cinco primers, resultando na média de 7,4 locos por primer. $\mathrm{O}$ alto polimorfismo encontrado $(97,2 \%)$ nas amostras de DNA representa a alta variabilidade existente entre os animais estudados das distintas localidades. Outros estudos sobre caracterização genética de ovinos com RAPD (KHALDI et al., 2010) e outras espécies de ruminantes (ALBUQUERQUE et al., 2006) mostraram resultados semelhantes, evidenciando que, mesmo com um pequeno número de marcadores é possível mensurar a variabilidade genética devido ao alto grau de polimorfismo dos mesmos.

Tabela 1. Primers de RAPD selecionados, com suas respectivas sequências, número de fragmentos amplificados e polimórficos. (NTLA $=$ Número total de locos amplificados em amostras de 164 ovinos; NTLP = Número total de locos polimórficos por primer considerando os 164 ovinos; $\mathrm{TP}=$ taxa de polimorfismo por primer)

\begin{tabular}{lcccc}
\hline Primer & Sequência & NTLA & NTLP & TP (\%) \\
\hline UBC 180 & 5'-GGGCCACGCT-3' & 7 & 7 & 100 \\
UBC 506 & 5'-CCTTTCCCGA-3' & 6 & 6 & 100 \\
UBC 549 & 5'-CCGGCTTATG-3' & 9 & 8 & 88,8 \\
UBC 556 & 5'-ATGGATGACG-3' & 8 & 8 & 100 \\
UBC 691 & 5'-AAACCAGGCG-3' & 7 & 7 & 100 \\
\hline Total & & 37 & 36 & 97,2 \\
\hline
\end{tabular}

Considerando a análise intrapopulacional, a taxa de locos polimórficos variou de $59,45 \%$ a $83,78 \%$ (média de 69,82\%) (Tabela 2), sendo a menor taxa encontrada na população de Redenção do Gurguéia e a maior em Bom Jesus. A redução entre a taxa de polimorfismo total $(97,20 \%)$ e intrapopulacional média $(69,82 \%)$ já era esperada, pois, na segunda estimativa, um número menor de indivíduos foram considerados para a avaliação $\left(\mathrm{n}_{\text {total }}=\right.$ 164 versus $\left.\mathrm{n}_{\text {médio/população }}=27,33\right)$. Entretanto, grandes diferenças entre esses valores podem indicar baixo nível de fluxo gênico entre populações ou baixo nível de diversidade intrapopulacional.

De forma geral, os valores de diversidade genética, medido pelo índice de heterozigosidade (Hs), revelam variação entre populações (Tabela 2). A estimativa apresentou menor valor para Teresina $(0,289)$ e maior para Bom Jesus $(0,342)$. No entanto, mesmo com esta constatação, esses valores podem ser considerados baixos, revelando a predominância de indivíduos homozigotos e concordando com as afirmações sobre a baixa 
Rev. Bras. Saúde Prod. Anim., Salvador, v.16, n.3, p.523-534 jul./set.., $2015 \quad \underline{\text { http://www.rbspa.ufba.br }}$

variabilidade intrapopulacional. Este fato pode estar atrelado ao uso de poucos reprodutores ou a produtos oriundos de acasalamentos endogâmicos entre meioirmãos, os quais levam ao aumento da endogamia no rebanho estudado, assim como já observado em análises prévias utilizando informações de pedigree (REGO NETO et al., 2013). Esta prática pode levar ao processo de "depressão endogâmica" que pode contribuir para a redução da produtividade de um rebanho (BREDA et al., 2004; CARNEIRO et al., 2007).

Tabela 2. Estimativa da diversidade genética para cada uma das seis populações de ovinos Santa Inês analisadas no presente estudo. ( $\mathrm{N}=$ tamanho da população; NTLP = número total de locos polimórficos por população; TP = taxa de polimorfismo por população; Hs = heterozigosidade; $95 \%$ IC = intervalo de confiança entre 2,5 e $97,5 \%$ )

\begin{tabular}{lcccc}
\hline Populações & $\mathrm{N}$ & NTLP & TP(\%) & $\mathrm{H}_{\mathrm{s}}(95 \%$ IC) \\
\hline Cristino Castro & 36 & 27 & 72,97 & $0,305(0,272-0,336)$ \\
Bom Jesus & 33 & 31 & 83,78 & $0,342(0,309-0,371)$ \\
Redenção do Gurguégia & 13 & 22 & 59,45 & $0,266(0,222-0,306)$ \\
São Raimundo Nonato & 22 & 28 & 75,67 & $0,288(0,245-0,324)$ \\
Teresina & 30 & 23 & 62,16 & $0,259(0,212-0,297)$ \\
Campo Maior & 30 & 24 & 64,86 & $0,269(0,229-0,305)$ \\
\hline Média por população & 27,33 & 25,83 & 69,82 & $0,289(0,254-0,315)$ \\
\hline
\end{tabular}

Os valores de Hs encontrados neste estudo (média de 0,289) foram um pouco abaixo dos valores encontrados por Paiva et al. (2003), também utilizando marcadores RAPD. Neste estudo foi obtida média de $\mathrm{Hs}=0,367$ para a raça Santa Inês em populações de Sergipe, Goiás e Distrito Federal, e Hs $=0,322$ para animais da raça Somalis. Esses resultados podem ser um indicativo da ocorrência de deriva genética em grupos pequenos ou aumento da endogamia. Neste caso, vale ressaltar que a perda contínua de diversidade genética de uma raça reduz a possibilidade de melhoramento genético futuro (EDING, 2001).

Corroborando com estes resultados, o índice de endogamia estimado $(f=$ $0,172$; I.C. $=0,010-0,492)$ indicou presença de endogamia dentro das populações em geral, podendo refletir, mais uma vez, os efeitos do pequeno número de machos reprodutores dentro dos rebanhos estudados. Como consequência direta, pode-se esperar o aumento da consanguinidade observada pela presença constante de meiosirmãos dentro das populações, sendo já constatada a redução do tamanho efetivo das populações da raça Santa Inês no Piauí (REGO NETO et al., 2014). Diante disso a raça encontra-se em estado de monitoramento no Estado, pois populações com tamanho efetivo reduzido têm maior probabilidade de perda da diversidade.

A prática de consórcio de reprodutores, se bem conduzida, pode ser estratégica para diminuir a endogamia acima do limite em rebanhos e favorecer o melhoramento genético da raça. Valores baixos de índices endogâmicos $\left(\mathrm{F}_{\mathrm{IS}}=\right.$ $0,005)$ foram observados em rebanhos Santa Inês de diversos estados brasileiros com a utilização desta estratégia (TEIXEIRA NETO et al., 2013). 
Outro fator resultante da endogamia dentro dos rebanhos é justamente o acúmulo de diferenças interpopulacionais. Essas diferenças foram avaliadas pelos índices $\theta_{\mathrm{II}}$ e $\Phi_{\mathrm{ST}}$, que apresentaram valores considerados de moderados a altos. Esses dados também explicam porque $\mathrm{o}$ alto grau de polimorfismo observado nos marcadores apresentou redução quando as amostras foram comparadas (a) em conjunto (com todas as amostras) e (b) dentro de cada fazenda separadamente (análise intrapopulacional). A análise de variância molecular (AMOVA) revelou que a maior parte da variação foi encontrada na amostra geral $(80,03 \%)$. Porém as diferenças entre populações podem ser consideradas altas e significativas, de acordo com os valores de $\Phi_{\mathrm{ST}}(0,199 ; \mathrm{P}<0,001)$. Considerando a organização das amostras entre Mesorregião Centro-Norte e Sudoeste do Piauí, a variação encontrada nos dados mostra que $8,42 \%$ desta pode ser explicada pela variação entre regiões $\left(\Phi_{\mathrm{CT}}=0,084 ; \quad \mathrm{P}<0,001\right)$. Por fim, observou-se que $11,55 \%$ da variação é explicada pelas diferenças encontradas entre populações dentro das regiões $\left(\Phi_{\mathrm{SC}}=0,126 ; \mathrm{P}<0,001\right)$.

As análises realizadas no programa STRUCTURE mostraram que as amostras estudadas podem ser organizadas em três grupos genéticos distintos, de acordo com as estimativas de Evanno et al. (2005) (Figura 2a). Além disso, mesmo com a subdivisão populacional sendo significativa e com a baixa heterozigosidade encontrada, há compartilhamento de alelos entre algumas populações, como Cristino Castro e Bom Jesus (Figura 2b). A única localidade que mostrou baixa introgressão de alelos foi da amostra colhida em uma fazenda em Teresina, onde também se observou a menor heterozigosidade. Este fato pode ser justificado pela localidade apresentar muitos animais ditos de rebanho "elite" utilizados para fins de exposição. Assim haveria maior preferência por acasalamentos utilizando sempre os mesmos reprodutores.

De acordo com o $\Phi_{\mathrm{ST}}$ par-a-par de cada localidade, as populações de Bom Jesus e Cristino Castro são mais assemelhadas, podendo esse ser um reflexo da proximidade entre os municípios $(36,2 \mathrm{Km})$, e consequentemente o uso de reprodutores aparentados (Figura $3 \mathrm{e}$ Tabela 3). Porém, outras populações que também estão geograficamente próximas mostraram alta divergência genética, como Redenção do Gurguéia e Cristino Castro $\left(\Phi_{\mathrm{ST}}=0,216\right.$; distância geográfica de $93 \mathrm{~km}$ ) (Figura 3 e Tabela $3)$. Nenhum outro grupamento formado seguiu padrão específico de estruturação que esteja relacionado com a posição geográfica das amostras, sendo este fato confirmado pelo teste de Mantel, que não apresentou resultados significativos $\left(r^{2}=0,30 ; \mathrm{P}=0,106\right)$. Como não se sabe da ancestralidade dos animais em questão, pode-se supor que o comércio de ovinos existente entre os municípios colabora com esse perfil genéticopopulacional. A falta de relação genética positiva encontrada entre os municípios de Teresina e Campo Maior (a apenas 81 $\mathrm{Km}$ de distância) também chamou a atenção. Entretanto, este dado pode ser apenas um reflexo da falta de relacionamento entre as fazendas amostradas ou, então, devido à aquisição de reprodutores geneticamente distintos. Porém, para ovinos, onde há manipulação antrópica, padrões de isolamento genético por distância não são tão óbvios quanto em populações naturais (SUN et al., 2007). 
Rev. Bras. Saúde Prod. Anim., Salvador, v.16, n.3, p.523-534 jul./set.., $2015 \quad \underline{\text { http://www.rbspa.ufba.br }}$

A

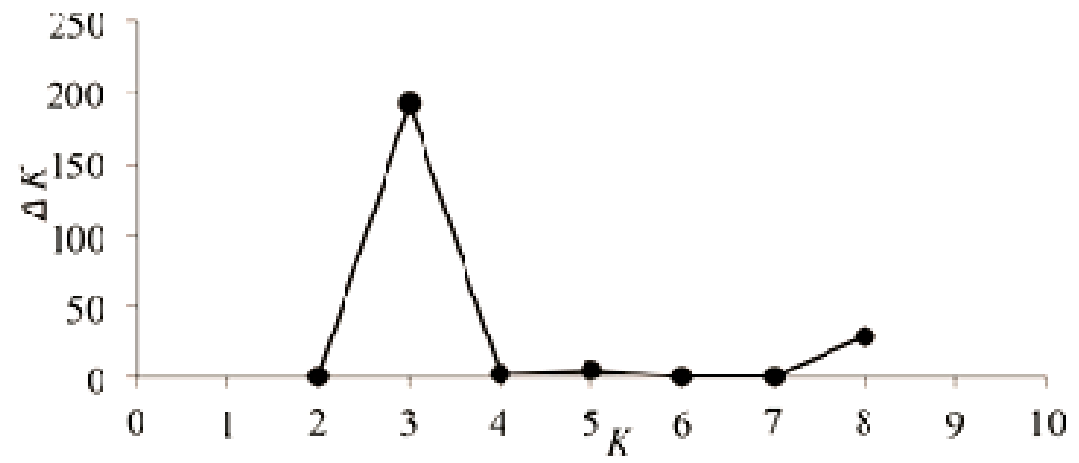

$\mathrm{B}$

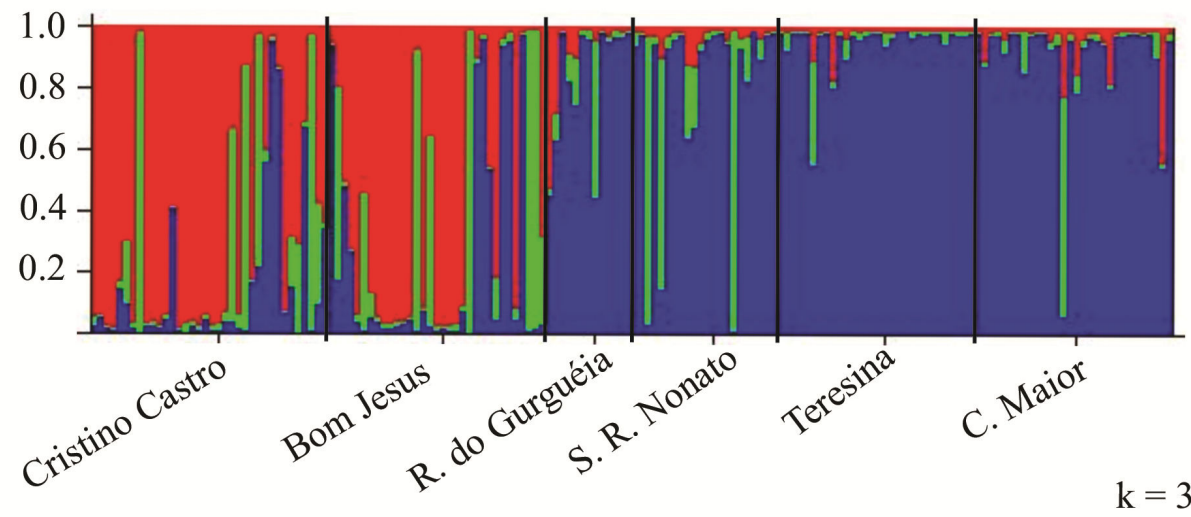

Figura 2. (a) Representação gráfica do $\mathrm{K}$ mais provável de acordo com os valores de $\Delta K$ (Evanno et al., 2005); (b) Designação das populações de Ovinos Santa Inês usando a estrutura baseada na alocação das amostras para $\mathrm{K}=3$

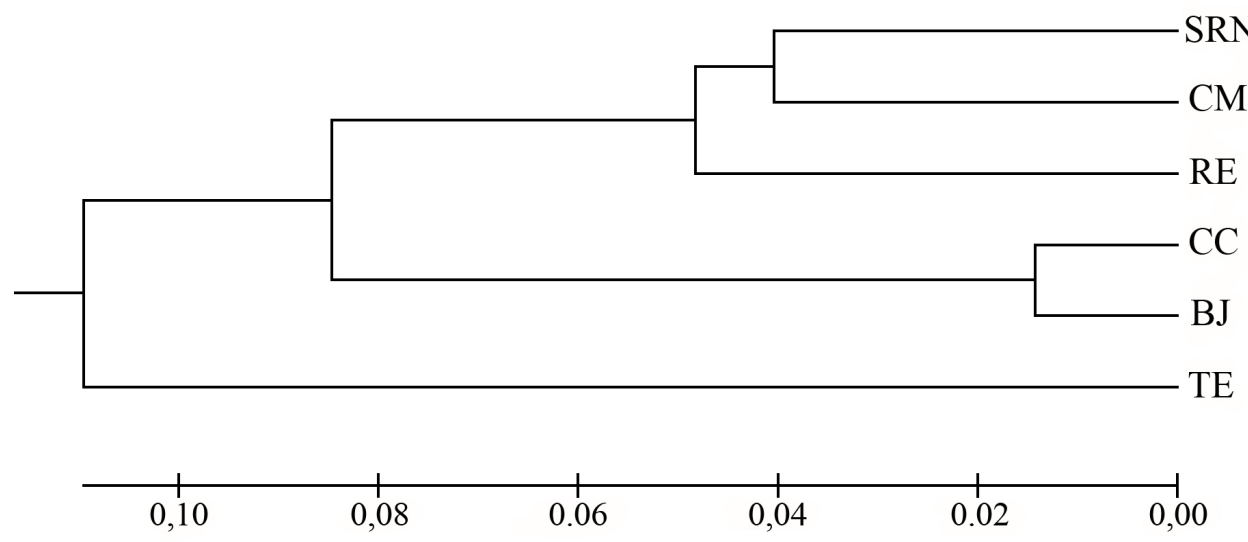

Figura 3. Dendrograma gerado pelos de valores de $\Phi_{\mathrm{ST}}$ par-a-par entre as populações, através do método UPGMA. SRN: São Raimundo Nonato, CM: Campo Maior, RE: Redenção do Gurguéia, CC: Cristino Castro, BJ: Bom Jesus, TE: Teresina 
Rev. Bras. Saúde Prod. Anim., Salvador, v.16, n.3, p.523-534 jul./set.., $2015 \quad \underline{\text { http://www.rbspa.ufba.br }}$ ISSN 15199940

Tabela 3. Distâncias genéticas par-a-par entre cada localidade estudada (valores de $\Phi_{\mathrm{ST}}$ na diagonal superior) e distâncias geográficas em quilômetros (diagonal inferior). CC: Cristino castro, BJ: Bom Jesus, RE: Redenção do Gurguéia, SRN: São Raimundo Nonato, TE: Teresina, CM: Campo Maior

\begin{tabular}{lcccccc}
\hline Item & CC & BJ & RE & SRN & TE & CM \\
\hline CC & - & 0,028 & 0,216 & 0,184 & 0,314 & 0,219 \\
BJ & 36,2 & - & 0,150 & 0,130 & 0,220 & 0,118 \\
RE & 93,9 & 59,3 & - & 0,096 & 0,257 & 0,097 \\
SRN & 226,0 & 245,0 & 303,0 & - & 0,187 & 0,081 \\
TE & 561,0 & 597,0 & 654,0 & 524,0 & - & 0,117 \\
CM & 641,0 & 677,0 & 735,0 & 576,0 & 81,4 & - \\
\hline
\end{tabular}

A estrutura das amostras nos três grupos indicados pelos cálculos de $\Delta \mathrm{K}$ pode estar relacionada com a presença de animais pertencentes ao "Novo Santa Inês", citado por Carneiro et al. (2010) e Paiva et al. (2005b). Estes autores concluíram que raças de ovinos nativos no Brasil eram intimamente relacionadas por terem ocorrido cruzamentos aleatórios no passado. Porém, a ação da deriva genética teria contribuído com o isolamento de algumas linhagens. Em Santa Inês foi observado que, em alguns casos, as distâncias genéticas entre populações da raça eram maiores do que a distância entre raças distintas, o que reforça a hipótese da existência de uma "velha raça Santa Inês" versus a "nova raça Santa Inês". Criadores e técnicos classificam a "velha Santa Inês" como animais mais rústicos e menores, que eram predominantes nas décadas de 1980 e 1990. A "nova Santa Inês" é descrita com o fenótipo que temos atualmente, como um animal de grande porte e bem desenvolvido. A justificativa mais provável para $\mathrm{o}$ surgimento desta seriam os cruzamentos com a raça Suffolk (McMANUS et al., 2010; CARNEIRO et al., 2010). Entretanto, análises conjuntas das informações fenotípicas são necessárias para confirmar a discriminação dessas duas linhagens entre os animais analisados no presente estudo. Como análise prévia, o grau de endogamia encontrado nos rebanhos amostrados corroboram com os resultados apresentados em outros estudos de pedigree (REGO NETO et al., 2014) ou com informações fenotípicas (COSTA JÚNIOR et al., 2006; BIAGIOTTI et al., 2013), reforçando a importância do monitoramento para a conservação do germoplasma ovino.

Este trabalho traz resultados preliminares sobre a estruturação e a diversidade genética de importantes rebanhos da raça Santa Inês localizados no Estado do Piauí. Foi observado que as fazendas amostradas apresentam diversidade considerável, porém os níveis de endogamia encontrados dentro de cada localidade devem ser levados em consideração para tomadas de decisões futuras, sendo a fazenda do município de Teresina considerada a mais endogâmica. Das seis fazendas amostradas nas Mesorregiões CentroNorte e Sudoeste, foram identificados três grupos genéticos distintos. Estas diferenças podem indicar a presença de animais tanto do chamado grupo "velho Santa Inês" quanto do "Novo Santa Inês" entre os indivíduos amostrados. 
Rev. Bras. Saúde Prod. Anim., Salvador, v.16, n.3, p.523-534 jul./set.., $2015 \quad$ http://www.rbspa.ufba.br ISSN 15199940

\section{AGRADECIMENTOS}

Agradecemos às valiosas considerações feitas pelo Dr. Marcos Jacob, Embrapa Meio-Norte, PI, que elucidaram muitos dos tópicos discutidos no presente trabalho.

\section{REFERÊNCIAS}

ALBUQUERQUE, M.S.M.; EGITO, A.A.; MARQUES, J.R.F.; CIAMPI, A.Y.; MARIANTE, A.S.; CASTRO, S.T.R.; COSTA, M.R.; PAIVA, S.R.; SILVA, A.M.; CONTEL, E.P.B. Variabilidade genética em búfalos estimada por marcadores RAPD.

Pesquisa Agropecuária Brasileira, v.41, n.4, p.623-628, 2006.

ARANDAS, J.K.G.; RIBEIRO, M.N.; PIMENTA FILHO, E.C.; DA SILVA, R.C.B.; FACÓ, O.; ESTEVES, S.N. Estrutura Populacional de Ovinos da Raça Morada Nova. In: SIMPÓSIO BRASILEIRO DE MELHORAMENTO ANIMAL, 9, 2012, João Pessoa. Anais... João Pessoa, 2012.

BIAGIOTTI, D.; SARMENTO, J.L.R.; DO Ó, A.O.; REGO NETO, A.A.; SANTOS, G.V.S.; SANTOS, N.P.S.; TORRES, T.S.R.; NERI,

V.S.Caracterização fenotípica de ovinos da raça Santa Inês no Estado do Piauí. Revista Brasileira de Saúde e Produção Animal [online], v.14, n.1, p.29-42, 2013.

BREDA, F.C.; EUCLYDES, R.F.; PEREIRA, C.S.; TORRES, R. de A.; CARNEIRO, P.L.S.; SARMENTO, R.L.; TORRES FILHO R. de A.; MOITA, A.K.F. Endogamia e limite de seleção em populações selecionadas obtidas por simulação. Revista Brasileira de Zootecnia, v.33, p. 2017-2025, 2004.
CARNEIRO, H.; LOUVANDINI, H.; PAIVA, S.R.; MACEDO, F.; MERNIES, B.; McMANUS, C. Morphological characterization of sheep breeds in Brazil, Uruguay and Colombia. Small Ruminant Research, v.94, p.58-65, 2010.

CARNEIRO, P.L.S.; MALHADO, C.H.M.; SOUZA JÚNIOR, A.A.O.; SILVA, A.G.S.; SANTOS, P.F. Desenvolvimento ponderal e diversidade fenotípica entre cruzamentos de ovinos Dorper com raças locais. Pesquisa Agropecuária Brasileira, v.42, p.991-998, 2007.

COSTA JÚNIOR, G.S.; CAMPELO, J.E.G.; AZEVÊDO, D.M.M.R; MARTINS FILHO, R.; CAVALCANTE, R.R.; LOPES, J.B.; OLIVEIRA, M.E. Caracterização morfométrica de ovinos da raça Santa Inês criados nas microrregiões de Teresina e Campo Maior, Piauí. Revista Brasileira de Zootecnia. v. 35, n.6, p. 2260-2267, 2006.

EDING, H. Conservation of genetic diversity: assessing genetic variation using marker estimated kinships. 2001. 79p. Thesis (Ph.D.in Animal Science) - Wageningen University, Wageningen.

EVANNO, G.; REGNAULT, S.; GOUDET, J. Detecting the number of clusters of individuals using the software STRUCTURE: a simulation study. Molecular Ecology. v.14, p.2611-2620, 2005.

EXCOFFIER, L.; LAVAL, G.; SCHNEIDER, S. Arlequin (version 3.0): An integrated software package for population genetics data analysis.

Evolutionary Bioinformatics Online, v.1, p.47-50, 2005. 
Rev. Bras. Saúde Prod. Anim., Salvador, v.16, n.3, p.523-534 jul./set.., $2015 \quad \underline{\text { http://www.rbspa.ufba.br }}$ ISSN 15199940

FARID, A.; O'REILLY, E.; DOLLARD, C.; KELSEY JR, C.R. Genetic analysis of ten sheep breeds using microsatellite markers. Canadian Journal of Animal Science, v.80, p.9-17, 2000.

GUIMARÃES, F.F.; REGO NETO, A.A.; ROCHA, L.M.C.; DO Ó, A.O.; BIAGIOTTI, D.; SARMENTO, J.L.R. Parâmetros populacionais de ovinos Santa Inês na região sul do Piauí. In: SIMPÓSIO BRASILEIRO DE MELHORAMENTO ANIMAL, 9, 2012., João Pessoa. Anais... João Pessoa, 2012.

HOLSINGER, K.E.; LEWIS, P.O.; DEY, D.K. A Bayesian approach to inferring population structure from dominant markers. Molecular Ecology, v.11, p.1157-1164, 2002.

KHALDI, Z.; REKIK, B.; HADDAD, B.; ZOURGUI, L.; SOUID, S. Genetic characterization of the three ovine breeds in Tunisia using randomly amplified polymorphic DNA markers. Livestock

Research for Rural Development, v.22, n.3, 2010 .

KUMAR, S.; NEI, M.; DUDLEY, J.; TAMURA, K. MEGA: a biologist-centric softwarefor evolutionary analysis of DNA and protein sequences. Briefings in Bioinformatics, v.9, p.299-306, 2008.

McMANUS, C.; PAIVA, S.R.; ARAÚJO, R.O. Genetics and breeding of sheep in Brazil. Revista Brasileira de Zootecnia, v. 39, p. 236-246, 2010.

MENEZES, M.P.C.; MARTINEZ, A.M.; RIBEIRO, M.N.; PIMENTA FILHO, E.C.; BERMEJO, J.V.D. Caracterização genética de raças caprinas nativas brasileiras utilizando-se 27 marcadores microssatélites. Revista Brasileira de Zootecnia, v.35, n.4, p.1336-1341, 2006.
PAIVA, S.R.; SILVÉRIO, V.C.; EGITO, A.A.; McMANUS, C.; FARIA, D.A.; MARIANTE, A.S.; CASTRO, S.R.; ALBUQUERQUE, M.S.M.; DERGAM, J. Genetic variability of the brazilian hair sheep breeds. Pesquisa Agropecuária Brasileira, v.40, n.9, p.887-893, 2005a.

PAIVA, S.R.; SILVÉRIO, V.C.; EGITO, A.A.; McMANUS, C.; FARIA, D.A.; MARIANTE, A.S.; CASTRO, S.R.; ALBUQUERQUE, M.S.M.; DERGAM, J. Caracterização Genética da raça Santa Inês. In: International Symposium on Sheep and Goat Production, 2, 2003, João Pessoa. Anais... João Pessoa: Empresa Estadual de Pesquisa Agropecuária da Paraíba, 2003. p. 487- 499.

PAIVA, S.R.; SILVÉRIO, V.C.; PAIVA, D.A. de F.; McMANUS, C.; EGITO, A.A.; MARIANTE, A. da S.; CASTRO, S.R.; ALBUQUERQUE, M.S.M.; DERGRAM, J. A. Origin of the main locally adapted sheep breeds of Brazil: a RFLP-PCR molecular analysis. Archivos de Zootecnia, v.54, p.395-399, 2005b.

PRITCHARD, J.K.; STEPHENS, M.; DONNELLY, P. Inference of population structure using multilocos genotype data. Genetics, v.115, p.945959, 2000.

REGO NETO, A.A.; SARMENTO, J.L.R.; SANTOS, N.P.S.; BIAGIOTTI, D.; SANTOS, G.V.; CAMPELO, J.E.G; SENA, L.S.; FIGUEIREDO FILHO, L.A.S. Estrutura e distribuição geográfica do rebanho de ovinos Santa Inês no Estado do Piauí.Arquivos da Escola de Medicina Veterinária da Universidade Federal da Bahia. Revista Brasileira de Saúde e Produção Animal [online], v.15, p.272-280, 2014. 
Rev. Bras. Saúde Prod. Anim., Salvador, v.16, n.3, p.523-534 jul./set.., $2015 \quad \underline{\text { http://www.rbspa.ufba.br }}$

RODRIGUES, D.S.; RIBEIRO, M.N.; OLIVEIRA, S.M.P.; LIMA, F.A.M.; VILLARROEL, A.B.S.; PACHECO, A.C.L.; SANTOS, L.H. Estrutura Populacional de um Rebanho da raça Morada Nova como contribuição para a conservação.Ciência Animal, v.19, n.1, p.103-110, 2009.

SILVA, R.C.B. da; PIMENTA FILHO, E.C.; RIBEIRO, M.N.; SILVA, E.C. da; FACÓ, O.; PAIVA, S.R. Diversidade genética de ovinos Morada Nova no estado do Ceará, Brasil. In: REUNIÃO ANUAL DA SOCIEDADE BRASILEIRA DE ZOOTECNIA, 48., 2011, Belém. Anais... Reunião Anual da Sociedade Brasileira de Zootecnia, 2011.

SUN, W.; CHANG, H.; JI, D.; LIAO, X.; DU, L.; LU, S.; KENJI, T. Distance of different ecological type sheep breeds in Mongolia sheep group.

Journal of Genetics and Genomics, v.34, n.11, p.1001-1009, 2007.

TEIXEIRA NETO, M.R.; DA CRUZ, J.F.; CARNEIRO, P.L.S.; MALHADO, C.H.M.; FARIA, H.H.N. Parâmetros populacionais da raça ovina Santa Inês no Brasil. Pesquisa Agropecuária Brasileira, v.48, n.12, p.1589-1595, 2013.

TENEVA, A. Molecular markers in animal genome analysis. Biotechnology in Animal Husbandry, v. 25, n.5-6, p.1267-1284, 2009.

VIANA, J.G.A. Panorama geral da ovinocultura no mundo e no Brasil. Revista Ovinos, v.4, n.12, p.44 - 47, 2008.
VIEIRA, O.R.; SIMPLICIO, A.A.; LEITE, E.R.; CIRIACO, A.L.T. Padrão Racial no melhoramento genético de caprinos e ovinos no Brasil. In: SIMPÓSIO NACIONAL DE MELHORAMENTO ANIMAL, 2000, Belo Horizonte. Anais... Belo Horizonte, 2000. p.191-193.

Data de recebimento: 16/01/2015 Data de aprovação: 09/09/2015 